\title{
ODIN, EL DIOS VIAJERO: La influencia de la Mitología Nórdica en la creación del Turismo
}

\author{
ODIN, THE WANDERER: The influence of Norse Mythology in the Tourism \\ creation
}

\author{
Maximiliano Emanuel Korstanje (KORSTANJE, M. E.)*
}

\begin{abstract}
RESUMEN - Dadas las condiciones ambiéntales necesarias, la segunda gran Guerra dio como resultados un crecimiento económico y una disponibilidad de consumo sin precedentes a la vez que un gran avance en la condición técnica de los países vencedores quienes, indudablemente, observan la creación de una nueva actividad en donde se "expande" el derecho a las vacaciones para una gran cantidad de segmentos, el turismo. Esta masividad es paralela no solo a la economía de consumo sino a la turistificación de las economías emergentes. Dentro de esta coyuntura, muchos historiadores apuntan al mundo greco-romano como el arquetipo ideal y cultural del turismo moderno y los viajes. Si bien la influencia de Roma en el mundo moderno es significativa, la tesis del presente trabajo es que el turismo tiene una gran influencia de la mitología y la hospitalidad germánica. Un dios viajero, una red de alianzas inter-tribales, y la creencia del mundo como un espacio cerrado a la voluntad humana hicieron de la mitología escandinava una pieza clave del turismo moderno. En perspectiva, la idea que todo viaje confiere sabiduría y fuerza (macht) superior es propia de esta cultura, y sienta la base para la creación medieval del Grand-Tour.
\end{abstract}

Palabras Claves: Movilidad; Predestinación; Hospitalidad; Turismo; Dios-Viajero.

ABSTRACT - Given the economic and social condition after the World War II, consumption and capital expanded worldwide to the extent of bringing many benefits to defeating countries. Undoubtedly, we are witness of the inception of a new reality based on the right of consumption that was materialized in the holidays and the touristification of developing economies. Although the eyes of historians are put to the Roman-World to denote the principle of mobility associated to travels and leisure, we argue that interesting discoveries can be done whether historians in tourism and hospitality fields turned their attention to Norse-Mythology. This paper stimulated a hot-debate in a point which merits to be studied in next layouts. Underpinned in the proposition that the principle of predestination and mobility were two key factors for the inception of tourism, the present work explored the contributions the mythology can exerts in tourism-related research. At a first glance, Norse-culture valorized the belief in an upmost God (Odin) whose nomadic nature led him to run across the world in shapes of different animals. In sharp contrast with scholars already assumed, travels as a form of discovery and conquest were coined 5 centuries before the advent of Roman Empire. The idea that every trip gives wisdom and power (macht) is typical of this culture and provides the basis for the creation of the medieval Grand-tour.

Key Words: Mobility; Predestination; Hospitality; Tourism; Travelling God.

\footnotetext{
* Licenciado en Turismo, Universidad de Morón. Diplomado superior en Antropología Social y Política (FLACSO). Ph D en Psicología Social (Universidad Argentina John F. Kennedy). Profesor Investigador. Editor en Jefe de la Revista International Journal of Safety and Security in Tourism and Hospitality. Center of Business Research and Studies. Av. Dorrego 169 - 2 Piso, ap. C. CP: 1414 - Buenos Aires Argentina. Universidad de Palermo (Argentina). E-mail: maxikorstanje@ fibertel.com.ar
} 


\section{INTRODUCCION}

La evolución histórica del turismo parece sujeta a la combinación de cuatro factores principales, la primacía técnica, el avance en medios de transporte suscitados luego de la Segunda Guerra, el aumento de los salarios y la reducción de las horas laborales (SESSA, 1979; KAHTCHIKIAN, 2000; GETINO, 2002; SCHLUTER, 2008; URRY, 2007). Si bien la literatura sociológica apunta al turismo como una construcción de la modernidad, existe evidencia arqueológica e histórica que sugiere muchas culturas anteriores tenían sus propias formas de evasión y, porque no también, de turismo. Para algunos especialistas, incluso, el sentido actual de movilidad ha sido un legado del Imperio Romano y del mundo de Homero (YASOSHIMA, J. R. y SILVA-OLIVEIRA, 2002; KORSTANJE, 2009; KORSTANJE y BUSBY, 2010). Por algún motivo, las cuestiones históricas, desde la edad media hasta la actualidad, se remontan una y otra vez al arquetipo romano como cuna de la civilización occidental (ESCALONAMUÑOZ, 2000).

No obstante, desde otra perspectiva se sugiere la movilidad ha sido un legado del mundo nórdico-germánico que debido a la característica ágrafa de su cultura ha sido ignorada por los historiadores del turismo. La cultura germánica se remonta hacia unos 2.000 años a la península de Escandinavia (norte de Europa), donde luego de misteriosas migraciones se desplazó hacia el sur, este y oeste del continente dando origen a tres ramas linguiísticas, germánico-nórdica, óstica y westica. Si bien sus estructuras míticas, cuentos y leyendas, todas de ellas basadas en el derecho consuetudinario, diferían entre así, el dios Odín o Wodan se encontraba presente como la máxima deidad. Esta figura tenía una peculiaridad interesante además de una gran sabiduría; su conocimiento era fruto de sus diferentes viajes por las comarcas humanas en donde disfrazado en forma de animal estaba en contacto con las costumbres de diferentes pueblos. Nadie en el mundo nórdico sabía con exactitud la forma de Odín pero muchos en sus relatos alegaban haber encontrándose con él. Por desgracia a diferencia del mundo greco-romano, los nórdicos no han dejado un corpus escrito de sus creencias y costumbres, hecho por el cual se hace difícil un rastreo sistemático de sus tradiciones. De todos modos, es claro existe una relación entre el conocimiento, la movilidad y el mundo salvaje que ha sobrevivido muchos milenios hasta la modernidad. 
Contradiciendo a los estudios precedentes en historia del turismo, la tesis que defiende el presente trabajo es que la movilidad, prerrequisito del turismo, ha sido una institución dada por el mundo nórdico. Sus estructuras mitológicas compartían ciertas semejanzas que pueden resumirse en a) la lucha incesante entre dioses y demonios como arquetipo entre el bien y el mal, b) el valor como forma de reconocimiento en la otra vida, c) el miedo a los muertos (sobre todo los enemigos) que perjudican a los vivos por medio del uso de su espíritu (también llamado fylgia), d) la pequeñez del hombre frente a la naturaleza, e) un rol preponderante de la mujer en la fijación de matrimonios, armisticios y ritos adivinatorios, y la creencia en una fuerza (Macht) que rige los destinos de todos los seres vivos e inanimados (MEUNIER, 2006).

Para arribar a una mejor comprensión del mundo escandinavo es necesario adentrarse en la noción de macht la cual era comprendida en analogía a la fuerza. En contraste con la cosmogonía románica, egipcia o la céltica, la germánica no poseía un pensamiento doctrinario articulado, ni jerarquías apoyadas por el culto a sus dioses. Por el contrario, sus estructuras de poder estaban centradas en la hazaña como criterio principal, la demostración de fuerza y la predestinación. Entre los antiguos nórdicos, existía la creencia en la fuerza de los seres vivos (Macht), cuya invocación podía ser activada por ciertas operaciones humanas, trayendo consigo beneficios o daños (MEUNIER, 2006). Asimismo, el Macht tenía la particularidad de no acabarse con la vida, sino que acompañaba al héroe hasta el mundo de los muertos. Desde una perspectiva antropológica, esta forma de construir su mitología, inherentes a grupos nómades, condicionaba las prácticas en el mundo profano exacerbando los logros y los méritos (sobre todo en la guerra) como elementos constitutivos de prestigio y autoridad. En este sentido, también las cosas (aun cuando no todas) poseían macht tales como el barco y la espada, lo cual explica no solo el motivo de porqué se les acostumbraba a poner nombre a ciertos objetos sino el apego los guerreros por sus armas. La enfermedad representaba, para estos hombres del norte, una disminución del poder o fuerza y conllevaba la invocación de las divinidades protectoras. Los ríos y el fuego también eran fuentes de divinidad y adoración, en parte debido a que se les atribuían virtudes purificadoras, profilácticas frente a las enfermedades y desastres. A menudo, los extranjeros en tanto que enviados de los dioses encarnaban un estado de tensión de difícil resolución. La aventura y los obstáculos que el viajero enfrentaba gracias a su 
valentía incrementaban el macht de una persona. Por tanto, el viaje implicaba no solo sabiduría sino búsqueda de reconocimiento social y poder. De la desgracia que simboliza la enfermedad y la pérdida del macht nace la hospitalidad.

\section{DISCUSIÓN CONCEPTUAL}

Con el paso de los años, los antropólogos han acordado que los mitos, lejos de ser leyendas infundadas como se creía, contribuyen notablemente a comprender científicamente la posición fenoménica del sujeto. Por medio de los mitos fundadores, los seres humanos construyen una red estereotipada de respuestas ante situaciones de peligro o incertidumbre. Para M. Mauss (2006), los mitos y rituales comparten una raíz similar en la cultura ya que pertenecen al sistema religioso. Sus funciones son simples a grandes rasgos, ayudar a los hombres a comprender el futuro y la incertidumbre dándoles una guía cierta para resolver y saltear los obstáculos tal cual lo han hecho sus predecesores (MAUSS, 2006). Para E. Evans Pritchard (1977), los mitos narran una era en donde los hombres y los dioses coexistían pacíficamente. Por motivo de una ruptura, esa relación ha llevado al hombre al trabajo alejándose del paraíso prístino. Desde esta perspectiva, los mitos concentran y antagonizan con dos realidades diferentes las cuales generan un problema a la humanidad. Los mitos y rituales representan en sí una contradicción del mundo y a la vez una forma correcta de resolución (EVANSPRITCHARD, 1977). Aquello que permanece fuera de la comprensión, debe ser apropiado por medio de una narrativa. En ese acto, explica C. Levi-Strauss, se articulan la finitud y la trascendencia como cuestiones básicas de la vida y la muerte (LEVISTRAUSS, 1991; 2003; 2002). Las diferentes etnologías, en este punto, demuestran como los mitos, en tanto estructuras, son proyecciones de los sentimientos, miedos, expectativas de las diferentes culturas y que entonces variando la cultura cambian los mitos. En consecuencia, los mitos no se comportan como estructuras inmutables sino que cambian acorde lo hace la propia sociedad hasta el punto de legitimar las prácticas sociales del momento (MALINOWSKI, 1998; LEACH, 1954; BALANDIER, 2004). Todo mito no solo es situacional sino que está condicionado por el contexto social que atraviesa. 
M. Eliade dice que los mitos pueden compararse con las forma de producción de una sociedad ya que su red de símbolos explican los diferentes procesos territoriales de parcelación y cultivo. Las necesidades de trabajo de la tierra se expresan por medio del proceso de cultivo, recolección de los frutos y destrucción para un nuevo cultivo. Mediante esta lógica, los mitos hablan de una creación (génesis), para una destrucción (fin de los tiempos) que llevará a una nueva creación (transformación). En consecuencia, los mitos son categorías de comprensión homologables a las formas productivas de expropiación y acumulación (ELIADE, 2006). Siguiendo el razonamiento de Eliade, Korstanje y Busby (2010) arguyen que el turismo en tanto actividad, anclada en un territorio, cuya característica central es la partida para un posterior retorno, puede ser estudiada científicamente si los investigadores se toman el trabajo de analizar los mitos fundadores de la religión judeo-cristiana (nuevo y viejo testamento). La Biblia, en este sentido, está plagada de metáforas y códigos que permiten no solo regular el descanso sino la movilidad como forma de evasión (principio punitivo). Cualquiera sea el caso, lo cierto es que en sus abordajes sobre el Cristianismo, Korstanje y Busby no examinan el papel de la mitología germánica en la configuración del turismo, y es entonces, en ese punto que el presente trabajo intenta ser un abordaje complementario.

\section{EL ORIGEN DEL TURISMO}

El turismo se comprende como una práctica subordinada al ocio. El alemán Erich Weber (1963) introduce (desde un prisma fenomenológico) tres elementos centrales que coadyuvan en la conformación del ocio: "la regeneración, la compensación y la ideación". La primera es necesaria tanto para la mente como para el espíritu y adquiere una tipología con arreglo al cansancio, ora sea parcial ora total. La compensación radica en la superación de obstáculos y frustraciones propias del ego y sus limitaciones. Finalmente, la ideación es la posibilidad de intuir ideas con cierto sentido y orientación normativa, cuya máxima expresión es el ocio contemplativo (WEBER, 1963). Para Joffre Dumazedier, el ocio debe ser comprendido como una parte del tiempo, disponible por el sujeto pero no por decisión personal sino por una triple causalidad que encuentra su expresión en la reducción de las jornadas de trabajo, la 
disminución de las obligaciones sociales y la relajación de los imperativos sociopolíticos (DUMAZEDIER, 1974). Frederic Munné (1999) establece un modelo que permite diagramar el tiempo social total. Mediante nociones básicas como condicionamiento y autodeterminación. Según su perspectiva, el tiempo social se divide en cuatro compartimentos interconectados: a) "tiempo psicobiologico", ocupado por aquellas conductas inevitables al mantenimiento de mente y cuerpo, b) "tiempo socioeconómico", lapso dedicado a todas aquellas actividades obligatorias y plausibles de retribución financiera como el trabajo, c) "tiempo sociocultural", dedicado a las acciones que refuerzan el sistema emocional y ambiental en la cual se desarrolla el sujeto como visitar amigos o asistir a un casamiento, y por último d) "tiempo libre", término asignado para aquel espacio temporal en donde el sujeto lleva a cabo todo tipo de acciones no condicionadas externamente. A su vez, estos tipos puros van entremezclándose entre sí a medida que las sociedades adquieren más complejidad (MUNEÉE, 1999). Dentro de la literatura psico-sociológica, las funciones del ocio alcanzan tres aspectos relacionados con el descanso, la diversión y el desarrollo de la personalidad. A la crítica fundada de Munné sobre la vaguedad de su definición, se puede agregar que Dumanzedier sólo hace referencia a un tipo de ocio surgido de la sociedad moderno-industrial y olvida que éste es una institución presente en la mayoría de civilizaciones antiguas (KORSTANJE, 2008).

La discusión sobre el momento propicio para el advenimiento del turismo como industria se remonta a mediados del siglo XX. Mientras algunos historiadores afirman que el turismo es una institución mucho más antigua de lo que se presupone, otra corriente considera al turismo como una creación post-segunda Guerra (KNEBEL, 1974; TORRE, 1980; YASOSHIMA y SILVA-OLIVEIRA, 2002; LEIPER, 1983). Tal vez, el debate no está bien planteado en términos dicotómicos. El turismo anglo-sajón moderno es, sin lugar a dudas, una construcción de la post-guerra pero no por ello se puede afirmar que no han existido otras formas de evasión u ocio, muy similares al turismo, en el pasado.

Originalmente, Buckard y Medlik (1981) habían propuesto un modelo para comprender la evolución del transporte y con éste del turismo. Como resultado de un clima prologado de prosperidad material y una revolución tecnológica, las sociedades occidentales desde 1840 comenzaron a experimentar una nueva tendencia a expropiarse 
del tiempo y espacio hasta el punto de moverse con libertad trascendiendo sus propias fronteras. Complementariamente, Sigaux (1965) plantea que dicho proceso de expansión dio lugar a una nueva forma de consumo que ha históricamente posibilitado las bases del capitalismo moderno. Entonces, no es extraño asumir que el capitalismo no solo se encuentra asociado a la movilidad sino al desarrollo de nuevas fuerzas productivas cuyo fin ha sido el entretenimiento. Torre (1980) propone un modelo de tres facetas para estudiar la evolución histórica del turismo moderno. La primera comprende desde la Edad Media hasta el siglo XIX. La segunda fase, denominada, de transición va desde el siglo XIX hasta el XX y se caracteriza por una "democratización" del turismo por medio del cual se expande la actividad a todas las clases sociales. Finalmente, la finalización de la Segunda Guerra comienza una nueva etapa donde esa democratización previa se transforma en masividad ubicando al consumo de ocio como un servicio obligado (derecho) a todo ciudadano. Si, como explica Getino (2002), el ocio era un valuarte distintivo de la vieja Europa, no fue hasta después de mediados del siglo XX que una cantidad mayor de personas comenzó a viajar por el mundo. Por su parte, Fernández-Fuster (1978) explica que etimológicamente el término turismo deriva del antiguo sajón Torn (Inglaterra), ampliamente difundido entre los campesinos para denotar la necesidad de un viaje con posibilidad de retorno. Este vocablo, a su vez, se bifurcaba en dos, Torn-us (sustantivo, el que da vueltas) y Torn-Are (verbo, dar vueltas). Particularmente, Torn puede ser comprendido como la precondición para expresar la necesidad de retorno en la Inglaterra medieval (FERNANDEZ-FUSTER, 1978). Para el siglo XVIII, los nobles ingleses utilizaban la palabra Torn para simbolizar sus viajes al exterior en donde, debían familiarizarse con las costumbres de otros pueblos para llegar a ser buenos gobernantes. Esta búsqueda de conocimiento para el posterior ejercicio político se expandió por toda Europa a otras noblezas dando origen a lo que los historiadores han llamado "Grand Tour". En este punto, la palabra Torn es remplazada por Tour de donde llegada la modernidad se simplificará en Tourism/Turismo y Tourist/Turist(a) (JIMENEZ-GUZMAN, 1986). Sin excepciones, la historia del turismo concibe a la movilidad y a los viajes como aspectos culturales del mundo Mediterráneo minimizando, incluso ignorando las contribuciones potenciales del mundo anglo y germánico antiguo. En las secciones siguientes, se examinarán las 
formas y evoluciones del turismo como así también sus aportes a la formación de una nueva forma de comprender la movilidad.

\section{4 ¿CÓMO SE EXPANDE LA MOVILIDAD EN EL MUNDO CAPITALISTA?}

Sin lugar a dudas, no hay mejor forma que comprender la evolución del turismo que adentrarse y discutir de fondo buenos trabajos en la materia, como ser el de la profesora E. Pastoriza (2011), quien presenta una historia sintetizada pero elocuente del turismo como parte de un fenómeno mayor al cual denomina ocio. Para el mundo moderno, el turismo se corresponde con las vacaciones y de la jerarquización de clase resultante. Inicialmente, E. Pastoriza (2011) recuerda en su trabajo "La Conquista de las vacaciones" la extraña tensión que se da en las primeras zonas de veraneo en la Argentina de fines de siglo XIX ya que uno de los mayores desafíos era adaptar las condiciones ambiéntales a los lugares de residencia de los viajeros con la suficiente familiaridad para no sentirse desguarnecidos, pero a la vez poder armonizar las costumbres las clases altas con respecto a un consumidor que comenzaba a perfilarse como masivo. De esta forma, el veraneo, costumbre propia de las clases más pudientes dio lugar a una forma menos estilizada producto de la cultura de masas, el turismo.

La conquista de las vacaciones, en la Francia de 1936, junto a los adelantos tecnológicos sentaron las bases para el advenimiento de una nueva forma de recreación que mediante el viaje generaba una gran expectativa. El proceso "democratizador" que implicó el turismo trajo beneficios ya que la cultura del veraneo (originalmente dada por 3 meses) se expandió por medio de un verdadero efecto demostración a otras clases, pero estas conquistas sociales trajeron ciertas fricciones y tensiones con otros grupos. Las antiguas pautas de distinción en el sentido de P. Bourdieu (2000) que antiguamente funcionaban como estrategias para mantener la propia identidad de clase, ahora estaban en disputa. Es decir, que en mayor o menor medida, desde su nacimiento el turismo parece haberse visto en una tendencia casi, si se quiere, contradictoria en la cual el encuentro entre visitantes y residentes cobra principal importancia. Según Pastoriza el turismo nace por dos aspectos constitutivos, el primero es la pérdida del temor al mar, visto como un lugar peligroso, por el cual se estructuraba la vida antes del siglo XIX o fines del XVIII con la corriente higienista. Ciertamente, los científicos recomendaban 
los beneficios del mar. Segundo, la fiebre amarilla y otras epidemias que asolaban las ciudades argentinas provocaron una rápida evasión a los barrios del norte de la ciudad de Buenos Aires y a las villas veraniegas. Siguiendo este razonamiento, entonces el veraneo se transformó en turismo solo cuando pudo ser democratizado. La tesis central de Pastoriza es que la historia del turismo "atravesó primero a las clases altas y muy aceleradamente involucró al conjunto de la sociedad en un proceso de democratización social, ya presente en los años veinte, que culminó con lo que José Luis Romero llamó la cultura de masas" (2011, p. 30). Pastoriza admite que si bien existen diferentes realidades, el turismo se expandió y se desarrolló de similar forma en todo el mundo. En consecuencia, esta inferencia le permite poder darle cierta universalidad a su teoría. La evolución y territorialización de la ciudad de Mar del Plata, en Argentina, puede ser una muestra de cómo el mismo fenómeno se llevó a cabo en otras ciudades.

En las secciones iniciales de su libro "La Conquista de las Vacaciones", Pastoriza analiza la evolución de las ciudades costeras como balnearios como así los aspectos socio-económicos que coadyuvaron en esa empresa. En el capítulo tercero, se toma el trabajo de visualizar la relación entre el montañismo y el higienismo como forma de cura para ciertas enfermedades. Pero dicha democratización generó tensiones entre las clases que se disputaban un espacio simbólico en la ciudad de Mar del Plata. El poder público por medio de la legislación y empresariado privado, mercado, combinaron esfuerzos no para dirimir esas diferencias sino para asignarle a cada grupo un territorio particular. En consecuencia, Pastoriza sugiere el turismo de masas pudo ser posible gracias al Peronismo por medio de la implementación de políticas sociales que posibilitaron una mayor influencia de viajeros. En los capítulos sucesivos, la historiadora explora otras formas de turismo que han prendido en Argentina como así también el proceso peronista donde se da una nueva reelaboración de la narrativa ligada al ocio, ya no para la ciudad de Mar del Plata sino para todo el país. La fuerza de los sindicatos junto a otros actores sociales, antes relegados, sugiere y confluye en la reconfiguración de un nuevo entramado social cuya función en el turismo encuentra una amplia legitimación.

El trabajo de Pastoriza, huelga decir, enfatiza en una evolución histórica de las diferentes formas turísticas en Argentina (pero siempre haciendo énfasis en los productos turísticos). El asenso social posibilitó el turismo se expandiera a otras clases 
sociales. Los Medios de transporte, cada vez más veloces, generaron una propensión para los traslados que facilitaron un ensanchamiento del mundo. De esta forma, la historiadora argentina se queja de los abordajes en la materia al punto que existe cierta indiferencia en la literatura sobre el papel de la democracia y su significado aplicado a los procesos de entretenimiento popular. La autora se da cuenta que el turismo, en tanto fenómeno derivado del ocio, tiene raíces sociales cambiantes dependiendo de las fuerzas de organización territorial que lo fundamentan, condicionan pero a la vez donde se plasman las expresiones culturales de las personas. Desde esta perspectiva el trabajo de Pastoriza se presenta como un serio intento, aunque fallido de comprender por medio del devenir de la historia la función del turismo. Incluso las buenas investigaciones, a veces, descansan en la lógica del "como sî" por lo cual es deber de la crítica señalarlos o por lo menos, ponerlos bajo la lupa crítica. En las siguientes líneas se pondrán en discusión los errores en tratamiento de Pastoriza (las cuales son también aplicables a la mayoría de los trabajos en turismo y hotelería):

1) Parece problemático aceptar que sólo después del siglo XVIII, con el higienismo, el hombre europeo se despojara de su temor al mar. El mundo mediterráneo antiguo de los siglos III al I A.C tenían una imagen positiva del mar. Cuenta Suetonio (1985) los Emperadores romanos se alejaban a su residencia en Capri para disfrutar el majestuoso paisaje que sólo el mar podía darles. Con el advenimiento de la Edad Media se cortaron las comunicaciones entre los feudos, y años de guerra frenaron con la movilidad que había nacido del Imperio Romano. El temor al mar había sido parte de ese tabú cultural impuesto por la descentralización de los feudos medievales. En otras palabras, se abandona el sistema político de Patronato romano para volver a la hospitalidad antigua (SUETONIO, 1985).

2) Concebir al turismo, como estrictamente, circunscripto a una ciudad o a la atractividad de un lugar no solo no se condice con la realidad del fenómeno, en tanto que institución social arcaica como dice Paoli (2007), presente incluso (con sus matices) en el alto imperio romano, sino que conlleva a la idea de comprender al turismo como un producto. Esta posición, nacida del Management europeo, concibe erróneamente que el turismo no ha existido desde siempre, sino que es una construcción moderna cuyas raíces sobrevienen de la segunda gran guerra. Las sociedades elaboran mecanismos discursivos para nivelar las contradicciones propias de la interacción cotidiana; el ocio 
es uno de ellos. De diferentes formas, no existe un turismo, sino varios turismo(s) cuya significancia lo ubica subordinado al subsistema onírico de cada grupo humano. Afirmar que sólo existe turismo cuando hay democratización es un error conceptual grave. Escalona-Muñoz (2000) ha hecho un trabajo más que convincente sobre la posición de la academia a considerar al turismo como un producto de la demanda en vez de un fenómeno social total. Esta perspectiva ilustra la forma en que los expertos han trivializado e ignorado antiguas formas de turismo ya sea occidentales como en caso grecorromano, como no occidentales para converger en una idea euro-céntrica del mismo.

3) Por desgracia, no puede visualizarse con claridad (en el trabajo de Pastoriza) un desarrollo exhaustivo de la palabra democratización y las implicancias que ella tiene. La gran contradicción de la democratización es que vuelva a la exclusión. Si "Democratizar" implica extender a otros grupos humanos un valor o práctica, entonces las aristocracias para mantener la distinción alteraran sus formas de relación para mantener la "diferencia". Dadas estas condiciones, una democratización conlleva hacia una aristocracia. Uno debería asumir, como dice Castoriadis (2006), la Democracia no implica extensión de derechos, ni mucho menos, sino simplemente que una asamblea pueda derogar una ley si la concebía injusta. Por lo expuesto, precisamente es la extensión de derechos que caracteriza al mundo espartano lo que homogeniza la dictadura, con piel de democracia. En consecuencia, no se puede hablar de democratización del turismo sino de masividad cuya función fue extender la hegemonía de las clases altas sobre el resto de la población, ya sea por efecto demostración u resistencia. Ha sido la tergiversación anglosajona de la democracia la que la ha llevado a una falsa utopia de la igualdad que nada tiene que ver con la democracia griega.

4) Por momentos, existe cierta sobre-valorización, si bien ha sido importante pero no decisivo, del peronismo como fenómeno de expansión del turismo, o de reconversión del veraneo al turismo, o de mistificación de Mar del plata como cuna del turismo nacional. Existe en Pastoriza como en otros autores, una tendencia a marplatearizar al turismo olvidando dos cuestiones importantes, el turismo europeo surge con T. Cook como una forma de ayuda al avance del alcoholismo en la Inglaterra industrial. Es decir, el turismo moderno se desarrolla en paralelo al abuso de sustancias y al agobio del trabajo propio del avance del capitalismo (SANTOS FILHO, 2008) (lógica de la 
burocratización weberiana). Ello sugiere a la actividad como válvula de escape y no como movimiento estético vinculado a la naturaleza in facto esse. Segundo, en Latinoamérica el turismo es importando por medio de un efecto demostración de las verdaderas clases aristocráticas que visitaban Europa (MARMORA, 2004). Mezcla de evasión y de efecto demostración el turismo europeo anglosajón finalmente desembarca en el Río de la Plata como lo hace en todo el mundo consolidándose finalmente junto del fordismo y al imperialismo estadounidense.

5) Pastoriza no reconoce el poder hegemónico del turismo, como forma estereotipada del ocio, en tanto que en el exacerbo de la movilidad, paradójicamente inmoviliza y crea subordinación económica (KORSTANJE y BUSBY, 2010).

La teoría del turismo en la actualidad, por el contrario, aborda al fenómeno desde una perspectiva holística permitiendo así una mayor comprensión del mismo. El sistema social se construye por medio de 5 subsistemas interconectados entre sí pero cuyas funciones difieren, "político" (acumula y dispersa poder), "económico" (regula la escasez), "mítico-religioso" (explica las incongruencias cosmogónicas por medio de la búsqueda de conocimiento), "geográfico" (mantiene la identidad, la seguridad y regula la permisividad de las fronteras) y "onírico" (absorbe las tensiones y conflictos generados por los otros cuatro subsistemas, y los sublima en forma de discurso unificado y hegemónico el cual nadie pone en duda). El ocio, precisamente, es parte del sub-sistema onírico y a la vez el turismo es una de las tantas formas de ocio pero su poder es aún mayor genera un discurso regulador de las voluntades individuales. La función principal del sistema onírico es la recreación como forma revitalizadora. Pero, como la ideología, su poder radica en la falta de oposición. Por ejemplo, nadie cuestionaría la movilidad de las sociedades occidentales como un derecho adquirido por medio de la fuerza y la expropiación; la movilidad como valor supremo cultural de Occidente se transmite a los niños en los diferentes canales de socialización desde pequeños y en las vacaciones (como espacio sagrado dado para la práctica del turismo) con fines de reproducción económica, e intereses políticos específicos. Asimismo, el subsistema geográfico juega un rol más que importante en la fijación de circuitos o canales donde viajar para recrearse se torna seguro o inseguro.

El entretenimiento, propio de todo viaje el cual alterna distensión con riesgo contenido y moderado, es la base del turismo como fenómeno total y aplicable a todas 
las culturas del planeta. Cuando existen inconsistencias ya sea generadas por el propio sistema o por un sistema o sociedad externo (es decir por un encuentro entre dos etnias), el ocio y el turismo no solo seguirán al discurso de la sociedad dominante, y con él al subsistema político, sino crearan una cosmovisión (gaze) con el poder simbólico suficiente para justificar el acto de expropiación. Cuando el sistema onírico no puede regular las bases de la homeostasis del sistema, deviene el cambio social. Por otro lado, el subsistema mito-religioso (donde entran aquellos sectores preservadores del saber como sacerdotes, científicos y periodistas entre otros) necesita de una fábula o historia para darle sentido al mundo y a los eventos que en él se suceden.

La mito-poiesis, o proceso de construcción mitológica, funda los valores culturales que van a dar sustento a la sociedad y alrededor de los cuales se van a crear los diferentes ritos, héroes y prácticas culturales. El vínculo entre el subsistema mitoreligioso y el onírico es de una elevada complejidad. Valores culturales que se presentan como incuestionables, a saber el descanso, la movilidad, el retorno, son esencialmente transmitidos por medio de los mitos de origen (génesis) y observables en las diferentes doctrinas religiosas del mundo. El viaje temporal por lo tanto requiere de una dislocación psíquica del viajero quien experimenta (en su fantasía) la necesidad de un cambio fabulado (dislocación identitaria) y posterior retorno a su matriz de origen. Por último y no por ello menos importante, la palabra vacaciones viene de un antiguo vocablo, "Ferias" (del latín feriae), similar al sentido de la licencia (hoy ferias es sinónimo de vacaciones en la mayoría de los lenguajes indo-arios) por medio de la cual millones de romanos que ocupaban funciones administrativas en la península regresaban a sus hogares temporalmente durante 3 meses situados en las diferentes provincias que conformaban el Imperio. Similares instituciones se observaban en el mundo Egipcio, Fenicio y hasta Sumerio.

\section{AVENTURA, ECONOMÍA Y BAQUETE}

El profesor Huizinga (1968) sostiene la creencia que lo lúdico y lo festivo se encuentra ligado para la mayoría de las lenguas de familia indo-europea. Como ya lo había hecho Lévi-Strauss (2003) en su Antropología Estructural, puede existir una relación causa-efecto entre las estructuras lingüísticas y las prácticas o sentidos sociales. 
Siguiendo este razonamiento, Huizinga parece entender algo similar y propone una comparación analítica entre el eje agonal-lúdico. Lo agonal, se refiere al dominio de lo festivo en el aspecto del juego una fusión de sentido para la representación escénica y el jugar, mientras que lo lúdico hace referencia (en los idiomas) a sentidos dispersos entre jugar y escenificar o festejar. El godo (gótico) de la familia óstica, designa al juego jah bilaikand ina en donde laikan hace expresa referencia al verbo saltar; en el antiguo anglo-sajón un término similar hace su aparición: lacan del viejo nórdico leika, leikr y lac o leka en donde se expresaban diversas clases de danzas corporales. Una última raíz lingüística hace referencia en el anglosajón a spelian o plegan (del cual derivan Spil, Spielen, y Spel), el cual hacía mención a "representar el papel de otro". No obstante, mientras en algunos grupos se mantuvo el tronco de Spelian en otros como el inglés moderno el término derivó en play (de plegan). Asimismo, plegan también adquiere una significación sacra en pflegen administrar justicia o agradecer, jurar etc. En este sentido, una tendencia desarrolla la raíz plegan hacia lo abstracto (pflegen como forma de comunión o celebración) y play, como forma concreta de juego (HUIZINGA, 1968).

En el mundo anglo-sajón, lo onírico se encuentra enraizado en play como forma libre de juego, mientras lo obligado en phlitan de donde vienen los términos pflicht y pledge como formas de obligación hacia o ir al combate infiriendo cierto peligro (también el franco pleige va en esa dirección). Una de las primeras aproximaciones al juego es su riesgo inherente. Si por último se analiza el término pflegen se obtiene tanto una significación de juego como de ceremonial. Como prueba, Huizinga considera que de esta raíz han surgido las palabras huweleec, huweleic (del actual holandés huwelijk) tanto que feestelic (fiesta) y vechtelic (combate en frisón) derivan del arcaico vocablo fyuchtleek. Por analogía, el autor sostiene que existe una relación entre las palabras mencionadas y laik (lac o lacan). Por regla general, un sujeto suele adentrarse al peligro por diversión aun cuando no es por el peligro en sí mismo que se arriesga, sino por la distinción que implica la competencia con otro. Acorde a lo expuesto, Huizinga remarca la idea que juego y peligro derivan del término plfegen que denota una idea de azar y libertad hasta el punto de vincularse a un final abierto ya que tanto en el juego como en la guerra el resultado parece sujeto a la competencia (HUIZINGA, 1968, p. $67)$. 
Luego de lo expuesto, se puede mencionar que las festividades eran consideradas eventos en donde todo el pueblo se reunía, para celebrar y realizar alguna ofrenda sagrada. Njord o Nerto, diosa de la tierra y su par Fricco (Frey), se convirtieron en los protectores de la tierra y de sus cultivos. La fertilidad de los campos, era comúnmente proclamada en conjunción con otras ceremonias como el matrimonio. En la fría Germania, las inclemencias climáticas, sequías o inundaciones implicaba una mala cosecha y por ende una migración segura. Es decir que la movilidad estaba determinada por el accidente. En ocasiones, una incursión por mar o río, traía diversos peligros y obstáculos que las adivinaciones podían prever. Los desplazamientos voluntarios hacia a lo desconocido en el mundo nórdico implicaba prestigio y status, ya que el viajero demostraba su valía e incrementaba su Macht (fuerza). Para aquellos que morían en el mar, existía la creencia de que continúan viviendo en él. No es extraño que aquellos elementos utilizados en las técnicas de adivinación como el agua o el fuego denotaran un miedo arcaico. Tanto el agua como el fuego, son útiles a las comunidades siempre y cuando sean controlados por la técnica. En la actualidad, Meunier afirma en muchos países de origen germánico el agua es un lugar de respecto y temor pues alberga a ciertos demonios que devoran a los viajeros. Cuanto más profunda sea el agua, mayor posibilidad de ser dañado por esta clase de espíritus (MEUNIER, 2006, p. 68). Sin embargo, el Macht asociado a otras figuras como berserkir (bravura) o el hamr (apariencia) existe la posibilidad de una metamorfosis (serkr) en donde los hombres se transforman en ciertos animales como lobos, osos etc. Estas expresiones de ambigua interpretación estaban vinculadas a la posibilidad de demostrar el pasaje del mundo humano al natural (DUMEZIL, 1958, p. 172).

De esta forma, el hamr comprendido como representación puede ser usado como vestido, una forma externa al cuerpo, un espíritu, suerte, una envoltura fundamental o el alma que se manifiesta en los sueños (Fylgia). El proceso de metamorfosis era simple, el cuerpo quedaba tendido en el suelo (generalmente ubicado bajo la protección de la selva o los árboles) en estado casi catatónico en tanto se transformaba en un pájaro o un animal furioso; su fuerza simbolizaba según el acholar la naturaleza animal del hombre. También como expresiones de ocio, era común el ofrecimiento de banquetes (alfablót) a los diferentes silfos (gnomos) que operaban en la tierra (landylfe), el agua (waeterlyfe) o el mar (seelyfe) o los vaettir (espíritus de tierra, agua y mar). Estos seres podían ser 
benefactores o sumamente vengativos para lo cual había que servirlos y ofrecer fiestas o celebraciones en su honor (para evitar su ira o Elfenschuss). Las tempestades y las tormentas tenían diferentes deidades que iban desde Irpa y Zorgerdr (al norte de Noruega) hasta las trollen o brujas en la Germania Meridional. Cuando un jefe de familia moría, en algunos pueblos, era enterrado o cremado junto a deliciosos manjares o con sus armaduras de combate.

La idea de morir en el camino de la aventura encierra toda una tipificación que encuentra en el banquete y en la hospitalidad su respuesta. A continuación se verán los elementos constitutivos de la hospitalidad - germánica y no germánica - vinculan la vida a la muerte, erotismo (fertilidad), alimento y bebida (economía), y sabiduría (como mecanismo de comprensión del otro y del mundo natural). De hecho, si se presta atención la palabra visa, deviene del latín videre que significa saber. Todo grupo humano debe "tener certeza" de quien está introduciendo en hospitalidad es inofensivo a la estabilidad del grupo. Por ese motivo, muchos relatos nórdicos vinculan la sabiduría al movimiento y a la hospitalidad.

\section{INTRODUCCIÓN A LA CULTURA NÓRDICA: EL ARQUETIPO DE WODAN/ODÍN}

Por desgracia, lo que hasta el día de hoy se conoce del mundo nórdico se debe a la intervención del Imperio Romano (Julio Cesar ha sido el primer etnólogo en documentar las costumbres de suevos y longobardos durante sus incursiones militares por Germania) (GERLOMINI, 2004). Desde una perspectiva etimológica no existe aún consenso acerca del origen de la palabra germano. Para algunos, el término viene del latín "Cormanus" que significa los que hablan con el corazón en la mano (tal vez por su franqueza) y aquellos quienes infieren su propensión a la guerra como industria primaria les valió la fama de grandes guerreros, de donde se desprende su nombre, "Heer" (guerra) "Mann" (hombre), en resumen "hombre de la guerra". Aun cuando esta discusión no está resuelta, se sabe las tribus germánicas se dividen en tres ramas, nórdicos (grupo compuesto por noruegos, suecos y daneses), orientales (situados en la 
actual Bulgaria y actualmente extinguidos) y occidentales (frisios, sajones, vándalos, y francos entre otros muchos); ¿es acaso el turismo un resultado de la guerra?.

La cultura occidental moderna, aunque no lo reconozca, le debe mucho al mundo nórdico antiguo. La tendencia a exacerbar el mundo romano y griego de la Edad Media ha sepultado el legado germánico hasta el punto de hacerlo invisible (KORSTANJE, 2009). Por su parte, diversos estudios han probado que las leyendas germánicas, a diferencia de las mediterráneas, consideraban al vínculo entre padre e hijo como inquebrantable a la vez que la posición de la mujer era activa, celebrando matrimonios y augures de guerra. Como el filial, el amor romántico, es, sin lugar a dudas una construcción germánica por su forma productiva. La actividad de las tribus germánicas y proto-germánicas se basaba en la movilidad como forma de subsistencia primaria. Su carácter nómade los obligaba a una constante guerra con sus vecinos, hecho por el cual, el trabajo se reservaba a las mujeres empujando a los hombres a defender las fronteras. El guerrero germano no tenía otra obligación más que la defensa. Si uno examina con atención los artículos dados para el trabajo en las lenguas romances, la mayoría de ellos son masculinos (il lavoro, el trabajo, etc) mientras que en lengua germánica son femeninos (die arbeit, det arbedtje etc). Por tratarse de tribus en constante movilidad y búsqueda de nuevos territorios, su capacidad para la agricultura era mínima como así también sus expresiones religiosas. Los antiguos nórdicos habían desarrollado un miedo muy profundo a los muertos (tal vez por su imposibilidad de permanecer en un territorio específico y la inoperatividad de llevarlos consigo). Su creencia en la fylgia, suponía que una persona podría retornar del más allá para tomar venganza por lo cual luego de una batalla y ante la imposibilidad de tomar esclavos, los capturados eran efectuados en formas rituales bien específicas. La fylgia no podía tomar forma mientras el enemigo fuera decapitado o cremado (JANSSON, 1997; MOBERG, 1989). Esta costumbre no solo horrorizó a los romanos sino que sentó las bases para la creación de toda una serie de estereotipos negativos en el Imperio sub-humanizando a estas tribus y simplificando el mundo nórdico. A diferencia de los romanos, las tribus germánicas comprendían al futuro como determinado por Odín y sus valkirias. Antes de entrar al campo de batalla, la suerte del guerrero y su performance en ella ya estaban echadas. Las valkirias descendían para llevarse a los caídos a las tierras del Valhalla donde quienes habían combatido con honor bebían y comían del jabalí eterno. El 
banquete y la hospitalidad son dos instituciones presentes en la antigua Germania (MEUNIER, 2006; WILKINSON, 2007; SOLA, 2004; KORSTANJE, 2009; ROBERT, 1992; TACITO, 1952; ANDERSON, 2009).

La hospitalidad es una construcción social que se remonta al siglo V A.C en la Europa antigua. Considerada una institución militar-política y religiosa, la hospitalidad ha tenido dos significados diferentes. Por un lado, funcionaba como una red de alianzas que en reciprocidad e igualdad de condiciones aliaba a las tribus en caso de ataque externo. Por el otro, la hospitalidad permitía a los sacerdotes comprender los designios divinos ante desastres naturales y catástrofes. Partiendo de la premisa que los dioses enviaban o se disfrazaban en forma de extranjeros para confirmar la buena voluntad de los receptores, una falta a un viajero extranjero podría ser vista como una ofensa grave y castigarse con la máxima dureza ya sea por una sequía o un desastre natural. La protección a los viajeros era de capital importancia para poder movilizarse por diferentes tierras sin necesidad de entablar relaciones de conflicto con las otras tribus. En este sentido, muchos historiadores antiguos han enfatizado en la hospitalidad como una forma eficiente de generar solidaridad entre los grupos humanos ya sea por el comercio o por la defensa conjunta (RAMOS y LOSCERTALES, 1948; D’ORS, 1953; RIVERO, 1993; HUMBERT, 1978; BALBIN-CHAMORRO, 2006). La guerra y la hospitalidad siempre han estado vinculadas entre sí. Mientras la primera confería todo el orden jerárquico de la sociedad y los valores culturales que la sustentaban, la segunda permitía un equilibrio con otros grupos humanos que le daba estabilidad a esa estructura social. El arma, como el museo moderno, tenía un doble sentido, dar orgullo a la comunidad por medio de la memoria, a la vez que generar motivos y significaciones de herencia.

Cabe destacar que los anglo-sajones y jutos tenían un apego especial con su espada. En ocasiones, cuando nacía un niño, el padre tomaba su espada y puesta frente a éste repetía "todo será tuyo todo aquello que puedas ganar con tu espada". En efecto, la espada no sólo representaba para estas tribus una forma de sustento, sino un tesoro familiar transmitido de generación en generación. Las relaciones familiares, de lealtad y de pertenencia para con su tribu se daba por la simbología de la espada (DAVIDSONELLIS, 1962). Por otro lado, y al igual que sus vecinos los galos y celtas, los nórdicos celebraban y respetaban la institución del hospicio, la cual consistía en establecer 
convenios entre pueblos para recibir recíprocamente a los viajeros pertenecientes a cada pueblo. En tiempos de guerra, el hospicio obligaba a los involucrados a ir a la guerra en forma conjunta. Esta institución no sólo era propia de los germanos, sino también de otras etnias de origen indo-europeo como los celtíberos y latinos. Los mismos hijos de Rómulo y Remo, fundadores de Roma, en sus orígenes celebraban hospicio aunque a medida que se fueron formando como Imperio dieron lugar a su contralor, el patronazgo.

J. Huizinga (1968) recuerda la importancia de la hospitalidad, el banquete y los juegos como mecanismos tendientes a entablar lazos de solidaridad entre los diferentes actores los cuales manifestaban una voluntad a futuro por medio de pactos y alianzas. Asimismo, la hospitalidad también implicaba un lugar de conflicto y tensión en donde ambas facciones podían desafiarse. El rol del anfitrión, en este sentido, era controlar, regular y disuadir a los comensales de no entrar en agresiones mutuas. Por lo tanto, la hospitalidad, sociológicamente hablando, puede ser comprendida como una institución milenaria cuyos fundamentos descansan en la idea de reducir la incertidumbre que da el ingreso de un extranjero del cual poco se sabe a la vez que (por medio del sexo, comida, bebida y música) disuade al extraño que su presencia es bienvenida. Cuenta la leyenda que Thor, hijo de Odín, fue seriamente reprendido por su padre luego de desafiar al gigante Hrungir en plena hospitalidad. Esta falta de respeto le valió ser expulsado del banquete, recordando al lector cuan importante era la hospitalidad en el mundo antiguo (DUMEZIL, 1958).

En los pueblos escandinavos la hospitalidad jugaba un rol principal como mecanismo de relación social y regulación de la violencia. Explica Huizinga, según los relatos de Alboin, la tribu de los Gépidos ha invitado con honores a los Longobardos (antiguos rivales) a un banquete por Turisindo (rey de los gépidos). Cuando éste último suspira por su hijo caído en combate en pugna con los Longobardos, su otro hijo comienza a insultar a los huéspedes llamándolos "yeguas de patas blancas". Uno de los comensales (de origen longobardo) se levanta y exclama "ve al campo de Asfeld, y allí te enterarás, sin duda alguna, de lo valientemente que cocean estos que tu llamas yeguas, allí donde los huesos de tu hermano se hallan dispersos. (HUIZINGA, 1968, p. 106”; inmediatamente el Rey pone orden mediando escénicamente entre los dos contendientes. Esta misma costumbre se encuentra presente según Huizinga en la 
leyenda de siglo X DC sobre el héroe dinamarqués Beowulf, y en las fiestas llevadas a cabo en los solsticios de invierno, conocidas como Yul. Esta lucha guionada a la cual Huizinga relaciona directamente con la capacidad lúdica de estas tribus, se la llamaba mannjafnaor la cual se basaba en ideas puramente religiosas de conexión entre anfitriones y huéspedes. Beowulf es una compilación, se cree, que simboliza los diferentes cambios lingüísticos e identitarios que estaban sufriendo las tribus germánicas en plena edad media, sobre todo la tensión entre la mitología pagana y el cristianismo. En la narrativa, uno de los mayores terrores que despierta del gigante Grendel, hecho por el cual Beowulf decide prestar sus servicios al rey Hrothgar, es su falta de hospitalidad al atacar a los guerreros mientras están bebiendo y comiendo en el "Hoff” (galpón) Canto I. Grendel es hijo ilegitimo de Hrothgar con una ogresa (KIERNAN, 1996). La reestructuración del mundo germánico, que denota la lucha constante entre sajones, frisios y francos situados entre el sur de Escandinavia y el norte de Jutlandia, y el rompimiento de los lazos familiares, entre familias constituidas e hijos legítimos, parecen ser dos de los principales temas en el relato. Asimismo, el espacio donde se llevan a cabo los hechos hablan del orgullo que representaba la "comensalía" o Hoff para la cultura germánica hasta el punto que lleva a un hombre a enfrentar a un ser "monstruoso". Este asentamiento tiene una importancia simbólica muy fuerte y abandonarlo, luego de los 12 años de ataques constantes por las noches, parece no ser una opción digna para el rey Hrothgar. El proceso de solidaridad por medio del cual Beowulf pone sus servicios en defensa del reino (seguridad interna), se asemeja a la hospitalidad antigua donde el linaje y los matrimonios mixtos cerraban el pacto (luego el héroe sajón, tras la muerte de Hrothgar, se casa con su mujer). Por último, el mundo natural, re-significado en forma de gigantes, ogros, troles y dragones es para la época un motivo de profundo temor.

Como ya se ha explicado, entonces se puede observar una conexión importante entre nomadismo, movilidad y hospitalidad en el mundo antiguo, pero no obstante, otras tribus no germánicas también practicaban la hospitalidad. Lo que distingue al mundo nórdico de otros, es no solo su propensión a moverse y la predestinación, sino la idea de configurar a su "Dios Supremo" como una deidad viajero que encuentra en esa movilidad su sabiduría. Dios regente de la tierra de Asgaard, Wodan (término derivado del antiguo ario wodanaz) es considerado el benefactor de la sabiduría y protector del 
comercio. Según la leyenda de Voluspá, Odín, fundó la tierra media (midgaard) junto a sus hermanos Ve y Vili. Para poder entrar a tierras de Odín, los hombres necesitaban del coraje y la destreza como dos aspectos principales de distinción. Destreza en los deportes y coraje demostrado en la batalla. A diferencia del hombre moderno quien teme a la muerte, el germano buscaba morir con honor "para vivir por siempre". Esta forma conceptual de concebir al otro y al mundo, llevó a los germanos a expandirse hasta límites impensados llegando a topar con celtas y romanos. Si el primer elemento constitutivo de Odín era la movilidad, la segunda ha sido la predestinación cuyo principio se caracteriza por desdibujar la obligación de los hombres hacia los dioses. Si en la mitología romana, los reyes ofrecían sacrificios a cambio de victorias, en el mundo nórdico la derrota o la victoria ya está plenamente determinada de antemano. La batalla no es la prueba sino el requisito necesario para acceder al más allá. En este punto, particularmente, M. Weber (2004) equivocó su teoría. No ha sido la ética protestante la fundadora del capitalismo sino la mitología germánica y su idea de mundo cerrado al futuro. La predestinación engendra un sentimiento de incertidumbre y ansiedad muy grande, simplemente porque el guerrero no sabe si es el elegido. Este sentimiento de frustración se alivia por medio del movimiento (FROMM, 2005). Mientras la movilidad es la condición primera del capitalismo, la predestinación es la causa de la movilidad.

Wodan/Odín acostumbraba a tomar forma de animales o cambiar regularmente de aspecto para emprender sus viajes por todo el mundo. En la saga de Ynlinga, él es descrito como un dios viajero cuya hambre de aventura y riesgos no tenía límites ya sea entrando a la tierra de Jotunheim con una identidad falsa o combatiendo contra gigantes o vanes, enemigos acérrimos de los dioses. En la tierra de Jotumheimr, Odín sacrifica su ojo tras beber del jarro de la sabiduría. En ese acto de dolor, los germanos rememoran la idea mítica que la sabiduría y el dolor están inextricablemente ligados. En forma comparativa a Adán y Eva u otros mitos, confieren a la creación la necesidad de saber, pero esa necesidad acelera la caída del hombre. Adán, Eva, Prometeo y Aquiles tienen en común esa búsqueda de voluptuosidad por la cual rompen el equilibrio natural. De la misma forma, el mito de Vegtam explica la comprensión del sufrimiento como pieza clave para la sabiduría. Sin lugar a dudas, el arquetipo del dios Odín figura toda una narrativa que culmina con el concepto de "Torn y más tarde" de Grand-Tour como se ha explicado en los párrafos precedentes. La mitología nórdica reemplaza la peregrinación, 
búsqueda de sacrificio judeo-cristiana ligada a la exploración, por la conquista propia de la expropiación. Mientras el peregrino, como explicaran en otros trabajos (KORSTANJE y BUSBY, 2010) son movidos por sus pecados y la necesidad de ser perdonados, los conquistadores intentan extender los límites de la civilización la cual sólo es posible combinando procesos cíclicos de construcción, para una destrucción para una nueva construcción. La escatología en el mundo nórdico es rica en relatos que vinculan la construcción como necesaria para la destrucción. El Ragnarok, escenario final de la lucha entre Vanes y Ases o dioses y contra-dioses, ilustra como los principales dioses mueren en manos de los vanes, y son vengados por sus respectivos hijos.

Para concluir, Snorri Sturlunson (1260), un monje islandés del siglo XIII ha sido uno de los primeros eruditos en compilar leyendas y relatos dispersos y transmitidos de generación en generación. Si bien son compilaciones tardías a la Germania de César, sus puntos centrales pueden ser explicados en tres ideas bien diferentes para una mayor comprensión del fenómeno. En primer lugar, existe una presencia sagrada por la cual los hombres son empujados hacia el futuro, esa fuerza es la predestinación; en segundo lugar, la movilidad es reconocida como un mecanismo de distinción social ya que trae consigo sabiduría y destreza. Por último pero no por ello menos importante, toda la literatura germánica está impregnada de un amor romántico hacia la mujer y una necesidad de conquista que conlleva a la idea de que el amor (por esa mujer) debe ser ganado por medio del sacrificio y el coraje. Las doncellas y los príncipes valientes, que han dado origen a toda una gama de formas de entretenimientos modernos como ser novelas, películas y deportes, se corresponden con esta matriz cultural. Las diferentes formas de ocio en Europa medieval como las carreras, combates e incluso las cruzadas a tierra Santa son prueba incuestionable de la tesis presentada en esta investigación (es importante para mayores detalles el trabajo de J. Huizinga (1968 sobre la búsqueda de competencia agonal del mundo Europeo). Si el macht sugiere la idea de "demostración" enraizada hoy día en el capitalismo moderno competitivo (hazaña), la idea de libre mercado se explica con la movilidad del capital. Si el futuro es determinado por la predestinación, la práctica es condicionada por el mercado de igual forma. 


\section{CONCLUSIÓN}

Si los historiadores del turismo prestaran atención a la mitología escandinava, se podrían hacer interesantes hallazgos. Este trabajo conceptual intenta comenzar un debate en la forma en que estos estudios deben ser hechos, pero de ninguna manera intenta imponer una metodología. Las contribuciones del mundo nórdico al moderno se vinculan por medio de la movilidad y la predestinación. En primera instancia, dichas leyendas articulan las creencias en un arquetipo de dios cuya naturaleza es principalmente nómada. En contraste con los historiadores del turismo, la idea de viaje como hoy se la conoce ha sido un legado del mundo anglosajón. Sin embargo, el viaje no puede ser posible sin un mecanismo que permita regular las dicotomías y contradicciones del mismo proceso, como lo es la hospitalidad. Este convenio ancestral entre grupos humanos afianza el proceso de solidaridad social a la vez que forma una idea de otro acorde a las propias creencias. Entonces, el turismo, en tanto que fenómeno social, obedece tanto al viaje (desplazamiento) como a la hospitalidad (en tanto que posibilidad de no ser atacado en ese viaje). Por sobre todo, por tratarse de una actividad comercial, la industria moderna de la hospitalidad y los viajes está conformada por la predestinación, el arquetipo de Odín y su movilidad como elementos significativos. Para concluir, es necesario romper con la idea que el mundo actual es una replica de Roma y Grecia. Existen otras culturas como los celtas, iberos, árabes, nórdicos y persas que explican la actual forma de concebir el mundo.

\section{REFERENCIAS}

ANDERSON, B. R. Norse Mythology. New York, S. C Griggs and Co, 2009.

BALANDIER, G. "Parentesco y Poder". En: Antropología Política. BALANDIER, G. (editor). Buenos Aires: Ediciones del Sol, 2004, p. 123-154.

BALBIN CHAMORRO, P. "Ius Hospitii y ius civitatis". Revista Gerión. Número 1:207-235, 2006.

BEOWULF. Leyenda Anónima. Poesía Épica. Compilación. Madrid, Alianza, 1986. 
BOURDIEU, P. La Distinción: criterio y bases sociales del gusto. Madrid, Taurus, 2000.

BUCKART, A. and MEDLIK, S. Tourism Past, present and future. Oxford, Heinemann Prof. Publishing, 1981.

CASTORIADIS, C. Lo Que Hace a Grecia: de Homero a Heráclito. Buenos Aires, Fondo de Cultura Económica, 2006.

DAVIDSON-ELLIS, H. The Sword in Anglosaxon England: its archaelogy and literature. Woodbridge, Boydell Press, 1962.

D`ORS, A. Epigrafía jurídica de la España romana. Madrid, 1953.

DUMAZEDIER, J. Sociologie empirique du loisir. Critique et contracritique de la civilisation du loisir. Paris, Editorial Du Seuil, 1974.

DUMEZIL, G. Dioses de los antiguos nórdicos. Berkeley: University of California Press, 1958.

ELIADE, M. The Myth of Eternal Return. Buenos Aires, Emece Editores, 2006.

ESCALONA-MUNOZ, F. "Economía del Ocio y trabajo no remunerado". Cuadernos de Relaciones Laborales. Vol. 17: 163-192, 2000.

EVANS-PRITCHARD, E. E. The Nuer. Barcelona, Editorial Anagrama, 1977.

FERNANDEZ-FUSTER, L. Teoría y técnica del turismo. Madrid, Editorial Nacional, 1978.

FROMM, E. El Miedo a la libertad. Buenos Aires, Paidos, 2005.

GERLOMINI, N. "Introduction". In Julius Caesar. Commentaries about the Galic Wars. Buenos Aires, Editorial Losada, 2004.

GETINO, O. Turismo: entre el ocio y el negocio. Buenos Aires, Ediciones Ciccus, 2002.

HUIZINGA, J. Homo Ludens. Buenos Aires, Emece editors, 1968.

HUMBERT, M. "Municipium et civitas sine sufragio. L'organisation de la conquete jusqu'a la guerre sociale". Roma, 1978.

JANSSON, S. B. Runes in Sweden. Varmamo, Falth Trikery, 1997.

JIMENEZ-GUZMAN, L. F. Teoría Turística. Un enfoque integral del hecho social. Bogota, Universidad externado de Colombia, 1986. 
KHATCHIKIAN, M. Historia del Turismo. Lima, Universidad San Martín de Porres, 2000.

KIERNAN, K. Beowulf and the Beowulf manuscript. Míchigan: University of Michigan Press., 1996.

KNEBEL, H. J. Sociología del Turismo. Barcelona, Editorial Hispano Europea, 1974.

KORSTANJE, M. "Notas fundamentales sobre estudios de ocio Antiguo". Revista Turydes: revista de investigación en turismo y desarrollo local. Marzo. Vol. 1. Número 2, 2008.

KORSTANJE, M. "The Cult of Deads. Influence of Norse mythology in the current terror movies". Revista Chilena de Antropología Visual. Vol. 13 (1), 2009.

KORSTANJE, M. and BUSBY, G. (2010). "Understanding the Bible as the roots of physical displacement: the origin of tourism". Ertr. Review of Tourism Research. Vol. 8 (3): 95-111, 2010. Available: at: $<$ http://ertr.tamu.edu/attachments/3090_Korstanje_Busby_The_Origin_of_Tourism.6.1 5.2010.pdf $>$.

LEACH, E. Political System of highland Burma. Londres, Bell, 1954.

LEIPER, N. “An Ethimology of Tourism”. Annals of Tourism Research. Vol. 10: 277$280,1983$.

LEVI-STRAUSS, C. Las Formas Elementales del Parentesco. Madrid: Paidos, 1991.

LEVI-STRAUSS, C. Mito y Significado. Madrid: Editorial Alianza, 2002.

LEVI-STRAUSS, C. El Pensamiento Salvaje. México: Fondo de Cultura Económica, 2003.

MALINOWSKI, B. Estudios de Psicología Primitiva. Buenos Aires, Editorial Altaya, 1998.

MARMORA, L. Las Políticas de Migraciones Internacionales. Buenos Aires, Editorial Paidos, 2004.

MAUSS, M. Manual de Etnografía. Buenos Aires, Fondo de Cultura Económica, 2006

MEUNIER, M. Mitología Nórdica. Libros de la Esfinge, Buenos Aires, Argentina, 2006.

MOBERG, V. A history of the Swedish People: from Prehistory to the renaissance. Nueva Yorrk, Dorset Press, 1989. 
MUNEE, F. Psicosociología del Tiempo Libre. México, Editorial Trillas, 1999, p. 7375.

PAOLI, U E La vida cotidiana en la Antigua Roma. Buenos Aires: Terramar Ediciones, 2007.

PASTORIZA, E. (2011). La Conquista de las Vacaciones: breve historia del Turismo en la Argentina. Buenos Aires, Edhasa.

RAMOS y LOSCERTALES, J. M. "Hospicio y clientela en la España Céltica". Revista Emerita 10. p. 308-337, 1948.

RIVERO, M. P. "El hospitium celtibero: estado de la cuestión". Universidad de Zaragoza. Ciclo II, 1993. Material disponible en: <http://155.210.60.15/HAnt/Hispania/hosp.celt.html >.

Extraído el 22 de Octubre de 2007.

ROBERT, J. N. Los Placeres en Roma. Madrid: Editorial Edaf, 1992.

SANTOS FILHO, J. dos. "Thomas Cook: marco da historiografia dominante no turismo. Ensaio sociológico sobre o preconceito ao fenômeno turístico na história". Turydes. Turismo y Desarrollo Local. Vol. 1(2): 1-15, 2008. Disponible en: $<$ http://www.red-redial.net/revista-turydes,turismo,y,desarrollo,local-202-2008-1-

$\underline{2 . h t m l}>$.

SCHLÜTER, R. Turismo: una versión integradora. Buenos Aires, Centro de Investigaciones y Estudios Turísticos, 2008.

SESSA, A. El Balance de la Investigación turística con implicaciones sociales en los últimos 25 años: ensayos de turismo. Bogotá: Bogotana Impresores, 1979.

SIGAUX, G. Histoire du Turisme, Ginebra, Edito-Service, 1965.

SOLA, M. D. Mitología Romana. Buenos Aires: Editorial Gradifico, 2004.

STURLUNSON, S. “Kringla Leaf”. Part of Heimskringla treasure 1. National Library of Iceland, displayed via The European Library, 1260.

SUETONIO, C. Los Doce Césares. Madrid, Editorial Sarpe, 1985.

TACITO, C. De las costumbres, sitio y pueblos de la Germania. Trad. C. Coloma. Obras Completas. Buenos Aires: Colección Clásicos Inolvidables, 1952.

TORRE, De la, O. El turismo, fenómeno Social. México, Fondo de Cultura Económica, 1980.

URRY, J. "Introducción, Culturas Móviles". En Viajes y Geografías. ZUSMAN, P. L. C. y CASTRO, H. (compiladoras). Buenos Aires, Prometeo, p. 17-31, 2007. 
WEBER, E. Das Freizeitproblem: Antropologisch-padagogische Untersuchug. Munich: Editorial Reinhardt, 1963, p. 193-250.

WEBER, M. Ética Protestante. Buenos Aires, Ediciones del Libertador, 2004.

WILKINSON, R. Norse Mythology and its meaning. Editorial Antropomórfica, Buenos Aires, Argentina, 2007.

YASOSHIMA, J. R. y SILVA-OLIVEIRA, N. "Antecedentes das Viagens e do Turismo". Em: REJOWSKI, M. Turismo no Percurso do Tempo. São Paulo, Aleph, 2002, p. 17-40.

Recebido em: 05-09-2011.

Aprovado em: 25-09-2011. 